\title{
SUPERAÇÃO DE DORMÊNCIA EM SEMENTES DE Brachiaria brizantha CV. MARANDU
}

\section{J. GARCIA ${ }^{1}$ \& S.M. CICERO ${ }^{2}$}

RESUMO: As tentativas de se efetuar a colheita de sementes de Brachiaria brizantha cv. Marandu por via mecanizada esbarraram em sua baixa germinaçăo, o que é atribuído à dormência. Em vista disso, o presente trabalho buscou encontrar alternativas para superar tal fenomeno. Para tanto, utilizaram dois lotes de sementes colhidas no cacho, manualmente, um deles oriundo de Neves Paulista-SP e o outro, de Goiania-Go. Amostras desses dois lotes foram submetidas aos seguintes tratamentos, (em delineamento experimental inteiramente casualizado, com quatro repetiçðes): substrato de germinação umedecido $\mathrm{com} 13 \mathrm{ml} \mathrm{de} \mathrm{H}_{2} \mathrm{O}$ (testemunha); substrato umidecido com $13 \mathrm{ml}$ de $\mathrm{KNO}_{3}$ a $0,2 \%$; sementes submetidas ao $\mathrm{H}_{2} \mathrm{SO}_{4}$ concentrado por 15 minutos, seguido de lavagem em água corrente por cinco minutos e substrato umedecido com $13 \mathrm{ml} \mathrm{de} \mathrm{H}_{2} \mathrm{O}$; semelhante ao anterior, sendo que o substrato foi umedecido com $13 \mathrm{ml}$ de $\mathrm{KNO}_{3}$ a $0,2 \%$; substrato umedecido com soluçāo de ácido 2-cloroetilfosfônico (etileno) a 10, 100 e $1000 \mathrm{ppm}$; e substrato umedecido com solução de ácido giberelico a 10, 100 e 1000 ppm. Após o teste de germinação constatou-se que o tratamento das sementes com $\mathrm{H}_{2} \mathrm{SO}_{4}$ mais $\mathrm{KNO}_{3}$ no substrato de germinação constitui a forma mais efetiva para superar a dormência em sementes de B.brizantha cr. Marandu.

Descritores: gramínea, forrageira, germinação, capim, dormência.

\section{OVERCOMING SEED DORMANCY IN Brachiaria brizantha CV. MARANDU}

ABSTRACT: Mechanized of harvesting of Brachiaria brizantha cv. Marandu seeds has resulted in high \% of dormant seeds. This work aimed at identifying laboratory procedures to overcome such dormancy. Two hand harvested seed lots of different origin were used in a completely randomized design, with four replications of each treatment. The treatments consisted of all possible combinations among sulfuric acid-treated (for 15 minutes) and non treated seeds with the wetting of the germination substratum with water, potassium nitrate, chloroethylphosphonic acid at 10,100 and $1000 \mathrm{ppm}$, or gibberelic acid at 10,100 and $1000 \mathrm{ppm}$. The highest germination percentages, as determined by the standard germination test, were obtained from sulfuric acidtreated seeds on top of potassium nitratewetted substratum.

Key Words: grass, forage, germination, seed quality, dormancy.

\section{INTRODUÇÃO}

As dificuldades crescentes no que se refere à utilização de mão-de-obra, fazem com que o produtor rural busque, tanto quanto possível, automatizar todos os processos agrícolas, em especial quando se trata de grandes áreas. Esta situação se torna mais aguda quando se considera a produção de sementes de gramíneas forrageiras, uma vez que, no Brasil Central, a maior parte dessas sementes é colhida pelo processo conhecido como "varredura".

No caso específico de B.brizantha cv. Marandu, a tentativa de colher as sementes mecanicamente resultou em fracasso, devido à baixa germinação e, assim, todo o material produzido tem sido obtido pelo método mencionado anteriormente. Além disso, ensaios levados a efeito na Estação Experimental da Empresa Goiana de Pesquisa Agropecuária de Goiânia, que buscavam identificar a maturidade fisiológica das sementes dessa gramínea forrageira, não tiveram sucesso, devido nãogerminação das sementes do cacho, mesmo quando armazenadas por dez meses.

Levando-se em conta a larga comercialização de sementes dessa gramínea forrageira, nos últimos anos, surge, a necessidade do emprego, em grande escala, de mão-de-obra, em face da não-germinação de sementes colhidas mecanicamente. Como as sementes

\footnotetext{
1 Prof. Adjunto do Departamento de Agricultura/EA da Universidade Federal de Goiás, Goiânia-Go.

2 Professor Associado do Departamento de Agricultura da ESALQ/USP, Piracicaba-SP.
} 
estudadas em Goiânia foram colhidas em diversas Epocas e armazenadas por diversos períodos, a não germinação sugere algum tipo de dormência especial, uma vez que esse fenômeno não foi superado naturalmente pelo armazenamento, como, em geral, ocorre com sementes de outras especies de gramíneas forrageiras.

CONDÉ \& GARCIA (1985), analisando o efeito de epocas de colheita sobre o potencial de armazenamento das sementes de Brachiaria decumbens cv IPEAN, puderam verificar que elas apresentaram dormência em qualquer época em que foram colhidas, e que a dormência foi superada naturalmente pelo armazenamento durante quatro meses. Resultado semelhante foi encontrado por JARK FILHO (1976), que, estudando a superação de dormência em sementes Brachiaria decumbens, observou que suas sementes perdem gradualmente a condição de dormentes com o decorrer do armazenamento.

Nesse ensaio, JARK FILHO (1976) submeteu as sementes aos seguintes tratamentos: remoção manual das glumas, remoção manual das glumas e glumelas, imersão das sementes intactas em ácido sulfúrico concentrado durante 10, 15, 20 e 30 minutos, e imersão de sementes intactas e sementes sem glumas em água destilada e em solução de diferentes concentrações de ácido giberélico, nitrato de potássio e peróxido de hidrogênio, durante 24 horas. Os efeitos dos tratamentos foram avaliados atraves do teste de germinação. $O$ autor concluiu que o tratamento de remoção manual das glumas e glumelas permite avaliar - potencial germinativo das sementes, independentemente do grau do dormência que apresentem. Com relação aos demais tratamentos, apenas 0 peróxido de hidrogênio mostrou-se relativamente eficaz. Os tratamentos restantes não resultaram numa promoção de germinação, tanto em sementes intactas como em sementes sem glumas. Resultados semelhantes foram obtidos por CARNEIRO \& MARQUES (1985), que removeram as glumelas de sementes de B.decumbens, provenientes de dois lotes, e submeteram-nas ao teste de germinação. Os autores verificaram que a retirada do lema e da pálea favoreceu a germinação de sementes de ambos os lotes; pelos resultados, constataram que já no sexto dia as sementes sem cobertura atingiram $95,4 \%$ de germinação, e não houve acréscimo até $026^{\circ}$ dia, tempo que durou o ensaio.

GOEDERT (1985) coletou amostras de Brachiaria humidicola e B.decumbens que foram imersas em ácido sulfúrico concentrado por $5,10,15$ e 20 minutos. A autora constatou que esse tratamento reduziu a germinação das sementes de B.humidicola. Constatou ainda que o tratamento promoveu um incremento de $50 \%$ na germinação de sementes de B.decumbens quando comparado com a testemunha, embora, aparentemente, tenha danificado parte das sementes. Resultados semelhantes foram obtidos por McLEAN \& GROF (1968), ao submeter sementes de Brachiaria mutica e B.ruziziensis ao ácido sulfúrico concentrado por 10,15 e 20 minutos, concluíram que - tratamento reduziu a germinação de sementes de B.mutica, embora tenha promovido um aumento na germinação de sementes de B.ruziziensis.

Muitos outros tipos de tratamentos são empregados para tentar superar a dormência em sementes de gramíneas forrageiras.

GOEDERT (1985), por exemplo, buscando superar a dormência verificada em sementes de Brachiaria humidicola, tratou amostras de sementes com azida sódica, cianureto de potássio, nitrato de potássio, ácido nítrico, peróxido de hidrogênio, etanol, tiuréia, 2-mercaptoetanol e ácido giberélico em diferentes concentrações. Os resultados mostraram que nenhum dos agentes estudados removeu a dormência de todas as sementes da população. Contudo, as mais altas percentagens de germinação foram obtidas com o uso do ácido giberelico.

A literatura disponível sobre o capim Marandu ainda não $\varepsilon$ muito ampla $e$, especificamente com relação ao tema abordado neste trabalho, nada pôde ser obtido no material bibliográfico pesquisado.

Assim o presente trabalho tem por objetivo encontrar alternativas para a superação da dormência em sementes de B.brizantha cv. Marandu.

\section{MATERIAL E MÉTODOS}

O trabalho foi desenvolvido com sementes colhidas em Neves Paulista-SP e Goiânia-GO. Os cachos foram colhido com o auxílio de cutelos, no momento em que se constatou o início da degrana natural. A seguir, foram submetidos à secagem natural à sombra, com posterior trilha manual das sementes. Estas também foram, complementarmente, secas à sombra até que atingissem 11-12\% de umidade. Posteriormente, sofreram beneficiamento e foram embaladas em sacos de papel e transportadas para o Laboratório de Análise de Sementes do Departamento de Agricultura da Escola Superior de Agricultura "Luiz de Queiroz", da Universidade de São Paulo.

Uma vez no laboratório, amostras de sementes de ambos os lotes foram submetidas aos seguintes tratamentos: 


\section{a) Testemunha}

Foram utilizadas sementes puras, sem qualquer acondicionamento. $O$ substrato de germinação foi umedecido com $13 \mathrm{ml}$ de água.

\section{b) Nitrato de potássio}

Sementes puras foram colocadas a germinar em substrato umedecido com $13 \mathrm{ml}$ de solução de $0,2 \%$ de $\mathrm{KNO}_{3}$.

\section{c) Ácido sulfúrico}

As sementes foram imersas em $\mathrm{H}_{2} \mathrm{SO}_{4}$ concentrado durante 15 minutos e, em seguida, lavadas em água corrente por 5 minutos e secas à sombra. $O$ substrato de germinação foi umedecido com $13 \mathrm{ml}$ de água.

\section{d) Ácido sulfúrico e nitrato de potássio}

$O$ procedimento assemelha-se ao do ítem anterior. A diferença consiste em umedecer o substrato com $13 \mathrm{ml}$ de solução de $0,2 \%$ de $\mathrm{KNO}_{3}$.

\section{e) Etileno $10 \mathrm{ppm}$}

As sementes puras foram colocadas a germinar sobre substrato umedecido com $13 \mathrm{ml}$ de solução de $10 \mathrm{ppm}$ de ácido 2-cloroetilfosfônico.

\section{f) Etileno $100 \mathrm{ppm}$}

O procedimento assemelhou-se ao ítem anterior. A diferença consistiu no umedecimento do substrato com uma solução de $100 \mathrm{ppm}$ de ácido 2cloroetilfosfônico.

\section{g) Etileno $1000 \mathrm{ppm}$}

O procedimento foi semelhante ao do ítem " $\mathrm{f}$ ", consistindo a única diferença no umedecimento do substrato de germinação com uma solução de 1000 ppm de ácido 2-cloroetilfosfônico.

\section{h) Ácido giberélico 10 ppm}

As sementes puras foram colocadas a germinar sobre substrato umedecido com $13 \mathrm{ml}$ de solução de $10 \mathrm{ppm}$ de ácido giberélico $\left(\mathrm{AG}_{3}\right)$.

\section{i) Ácido giberélico 100 ppm}

O procedimento assemelhou-se ao do ítem anterior. A diferença consistiu no umedecimento do substrato com uma solução de $100 \mathrm{ppm}$ de ácido $\left(\mathrm{AG}_{3}\right)$.

\section{j) Ácido giberélico $1000 \mathrm{ppm}$}

O procedimento foi semelhante ao do ítem "i", sendo que a única diferença no umedecimento do substrato de germinação com uma solução de 1000 ppm de ácido $\left(\mathrm{AG}_{3}\right)$.

Para o teste de germinação do material oriundo dos diversos tratamentos,colocaram-se as quatro repetições de 50 sementes, colocadas em caixas plásticas tipo "gerbox", sobre substrato constituído de duas folhas de papel mata-borrão, as quais foram colocadas em germinador com temperatura de $20^{\circ} \mathrm{C}$ por 16 horas (sem luz), alternada com oito horas a $35^{\circ} \mathrm{C}$ (com luz branca). As contagens foram efetuadas aos 7 , 14 e 21 dias após a instalação do teste.

$O$ delineamento experimental utilizado foi o inteiramente casualizado, com quatro repetições.

\section{RESULTADOS E DISCUSSÃO}

Nas Tabelas 1 e 2 encontram-se as médias de germinação das sementes submetidas aos diversos tratamentos.

A análise estatística dos dados indica uma supremacia destacada do tratamento associado de $\mathrm{H}_{2} \mathrm{SO}_{4}$ e $\mathrm{KNO}_{3}$ em ambos os lotes. De forma análoga, também para os dois lotes o segundo tratamento de maior eficiência foi a utilização de $\mathrm{H}_{2} \mathrm{SO}_{4}$, embora este não tenha diferido significativamente do tratamento que se lhe seguiu. Os demais tratamentos não se manifestaram igualmente em ambos os lotes, embora tenha havido uma tendência de que os tratamentos que envolveram o $\mathrm{AG}_{3}$ apresentarem um efeito intermediário (na ordem decrescente de efetividade dos tratamentos) no estímulo à germinação, enquanto os tratamentos que envolveram - etileno apresentaram uma tendência de se situarem como os mais ineficientes, não diferindo estatisticamente da testemunha.

A presença de $\mathrm{H}_{2} \mathrm{SO}_{4}$ nos dois tratamentos com melhores resultados sugere uma dormência física na cobertura da semente. Com relação a esse fenômeno, OPINIGIS (1977) afirmou que a impermeabilidade ao oxigênio é encontrada em muitas espécies de gramíneas, acrescentou ainda, que determinadas estruturas, tais como pericarpo, tegumento e mesmo paredes celulares, restringem as trocas gasosas.

De outra parte, o grande incremento que o $\mathrm{KNO}_{3}$ promoveu na germinação de sementes tratadas com $\mathrm{H}_{2} \mathrm{SO}_{4}$, por sua vez, sugere mais uma forma de dormência: química, desta feita. Com referência a esta constatação, CARVALHO \& NAKAGAWA (1983), informam que na maioria dos casos em que $\circ \mathrm{KNO}_{3}$ atua efetivamente na superação de dormência, isso ocorre em sementes de gramíneas, pois, nelas, a dormência seria devida à ocorrência de substâncias 
fixadoras de oxigênio no complexo película-pericarpo (compostos fenólicos).

Tabela 1 - Teste de germinação de sementes colhidas em São Paulo: médias obtidas para o efeito de tratamentos.

\begin{tabular}{||ll|}
\hline Tratamentos & Germinação (\%) \\
\hline $4 \mathrm{H}_{2} \mathrm{SO}_{4}+\mathrm{KNO}_{3}$ & $35,48 \mathrm{a}^{*}$ \\
$3 \mathrm{H}_{2} \mathrm{SO}_{4}$ & $18,29 \mathrm{~b}$ \\
$9 \mathrm{AG}_{3} 100$ & $13,56 \mathrm{~b}$ \\
$10 \mathrm{AG}_{3} 1000$ & $7,51 \mathrm{bc}$ \\
$2 \mathrm{KNO}_{3}$ & $6,00 \mathrm{bc}$ \\
$8 \mathrm{AG}_{3} 10$ & $2,81 \mathrm{~cd}$ \\
$5 \mathrm{ET}_{10}$ & $2,26 \mathrm{~cd}$ \\
$7 \mathrm{ET} 1000$ & $1,84 \mathrm{~cd}$ \\
$6 \mathrm{ET}_{100}$ & $1,46 \mathrm{~cd}$ \\
$1 \mathrm{H}_{2} \mathrm{O}$ & $1,13 \mathrm{~d}$ \\
\hline
\end{tabular}

Tabela 2 - Teste de germinação de sementes colhidas em Goiás: médias obtidas para o efeito de tratamentos.

\begin{tabular}{||lc||}
\hline \multicolumn{1}{|c||}{ Tratamentos } & Germinação (\%) \\
\hline $4 \mathrm{H}_{2} \mathrm{SO}_{4}+\mathrm{KNO}_{3}$ & $29,95 \mathrm{a}^{*}$ \\
$3 \mathrm{H}_{2} \mathrm{SO}_{4}$ & $14,89 \mathrm{ab}$ \\
$2 \mathrm{KNO}_{3}$ & $10,84 \mathrm{~b}$ \\
$10 \mathrm{AG}_{3} 1000$ & $6,91 \mathrm{bc}$ \\
$9 \mathrm{AG}_{3} 100$ & $6,85 \mathrm{bc}$ \\
$8 \mathrm{AG}_{3} 10$ & $5,46 \mathrm{bc}$ \\
$1 \mathrm{H}_{2} \mathrm{O}$ & $1,84 \mathrm{~cd}$ \\
$6 \mathrm{ET} 100$ & $1,46 \mathrm{~cd}$ \\
$5 \mathrm{ET} 10$ & $0,94 \mathrm{~d}$ \\
$7 \mathrm{ET} 1000$ & $0,12 \mathrm{~d}$ \\
\hline
\end{tabular}

Conforme pode-se verificar na revisão de literatura, a utilização de $\mathrm{H}_{2} \mathrm{SO}_{4}$ na superação de dormência de sementes apresenta resultados contraditórios, podendo tanto favorecer como prejudicar a germinação de sementes. Isso vai depender, grandemente, da espécie e do histórico das sementes.

$\hat{E}$, também, pertinente registrar, a grande quantidade de fungos verificadas no substrato de germinação das sementes, tratadas com $\mathrm{H}_{2} \mathrm{SO}_{4}$, embora a quantidade de plântulas anormais tenha sido relativamente pequena.

Outra observação interessante refere-se a uma expressiva germinação verificada numa contagem efetuada na quinta semana de instalação do teste (portanto, já tendo sido terminado o período de coleta de dados), em sementes tratadas com $\mathrm{AG}_{3} 100 \mathrm{ppm}$.

Este trabalho permitiu abrir perspectivas para outros ensaios, como por exemplo: o teste de outros produtos, com outras dosagens e combinações; avaliar a interferência de fungos no processo germinativo: submeter a uma base forte as sementes tratadas com $\mathrm{H}_{2} \mathrm{SO}_{4}$, e avaliar possíveis interferências na germinação, no substrato e na presença de fungos.

\section{CONCLUSÃo}

Concluiu-se que dentre os tratamentos utilizados a aplicação de $\mathrm{H}_{2} \mathrm{SO}_{4}$ por 15 minutos (seguida de lavagem por 5 minutos), com posterior adição de $\mathrm{KNO}_{3} \quad 0,2 \%$ no substrato de germinação, é a forma mais efetiva para superar a dormência das sementes de B.brizantha cv. Marandu.

\section{REFERÊNCIAS BIBLIOGRÁFICAS}

CARNEIRO, J.W.P. \& MARQUES, F.V. Influência da retirada da cobertura protetora no desempenho de dois lotes de sementes de capim braquiária. In: CONGRESSO BRASILEIRO DE SEMENTES.4., Brasilia, 1985. Resumos. Brasilia, ABRATES, 1985. p.81.

CARVAlHo, N.M. \& NAKAGAWA, J. Sementes: ciência, tecnologia e produção. Campinas, Fund. Cargill, $2^{\mathrm{a}}$ ed. rev. 1983. 429p.

CONDÉ, A. dos R. \& GARCIA, J. Efeito da época de colheita sobre o potencial de armazenamento das sementes de capim braquiária em condições ambientais. Revista Brasileira de Sementes, Brasilia, 7(2):85-92, 1985. 
GOEDERT, C.O. Efeito de reagentes químicos na superação da dormência em sementes de gramíneas forrageiras. In: CONGRESSO BRASILEIRO DE SEMENTES, 4., Brasilia, 1985. Resumos. Brasilia, ABRATES, 1985. P.66.

JARK FILHO, W. Estudo sobre a quebra de dormência em sementes de Brachiaria decumbens Stapf. Piracicaba, SP, ESALQ/USP, 1976. 63p. Dissertação de Mestrado.

McLEAN, D. \& GROF, B. Effect of seed treatments on Brachiaria mutica and Brachiaria ruziziensis. Queensland Journal of Agricultural and Animal Science, Queensland, 25:81-3, 1968.

POPINIGIS, F. Fisiologia da Semente. Brasilia, AGIPLAN, 1977. 290p. 